Bài báo khoa học

\title{
Diễn biến chất lượng nước mặt vùng bờ thành phố Hồ Chí Minh giai đoạn 2016-2019
}

\section{Lê Ngọc Tuấn ${ }^{1 *}$, Đoàn Thanh Huy ${ }^{2}$}

${ }^{1}$ Trường Đại học Khoa học Tự nhiên, Đại học Quốc gia Thành phố Hồ Chí Minh; lntuan@hcmus.edu.vn

${ }^{2}$ Viện Khí tượng Thuỷ văn Hải văn và Môi trường; dthanhhuy132@gmail.com

*Tác giả liên hệ: Intuan@hcmus.edu.vn; dthanhhuy132@gmail.com

Ban Biên tập nhận bài: 12/4/2020; Ngày phản biện xong: 24/5/2021; Ngày đăng bài: $25 / 7 / 2021$

Tóm tắt: Trong bối cảnh gia tăng dân số và phát triển kinh tế mạnh mẽ tại lưu vực sông Sài Gòn-Đồng Nai, chỉ số WQI (Việt Nam) và CCME (Canada) được sử dụng nhằm đánh giá diễn biến chất lượng nước (CLN) vùng bờ thành phố Hồ Chí Minh (TpHCM) giai đoạn 2016-2019 (theo mực nước triều, tháng, mùa và năm) trên cơ sở dữ liệu quan trắc định kì (14 trạm) và đo đạc bổ sung (22 trạm). Nhìn chung, CLN tốt dần về phía biển, đáp ứng các mục tiêu CLN (ngoại trừ $\mathrm{Pb}$ ở hạ lưu sông Vàm Cỏ, sông Lòng Tàu và TSS ở vùng cửa sông, ven biển). CLN ở thời điểm triều rút thường kém hơn khi triều cường (rõ nét tại các sông nội đồng); mùa mưa (mức trung bình-khá) thường kém hơn mùa khô (mức khá-tốt). Gần đây ghi nhận dấu hiệu cải thiện CLN tại một số vị trí cửa sông và vùng ven biển, tuy vậy, cần thiết tăng cường và duy trì liên tục công tác quản lý $\mathrm{CLN}$ vùng bờ $(\mathrm{pH}, \mathrm{DO}, \mathrm{N}-$ $\mathrm{NH}^{+}$, Coliform, E.Coli, $\mathrm{Pb}, \mathrm{Mn}$ ), nhất là thượng nguồn sông Lòng Tàu, hạ nguồn sông Soài Rạp, cửa sông Đồng Tranh...Bên cạnh đó, khuyến nghị sử dụng chỉ số CCME trong đánh giá CLN vùng bờ nhằm xem xét đồng thời $C L N$ khu vực lục địa và vùng biển ven bờ. Để tăng cường hiệu quả quản lý, cần tiếp tục nghiên cứu tình hình phát thải, dự báo xu thế CLN và khả năng chịu tải của khu vực.

Từ khóa: Chỉ số chất lượng nước, Ô nhiễm môi trường, Nước mặt, Vùng bờ.

\section{1. Đặt vấn đề}

Chất lượng nước $(\mathrm{CLN})$ thể hiện sự thích hợp của nguồn nước để duy trì các chu trình lý-hóa-sinh trong nước và phục vụ các mục đích sử dụng khác nhau [1]. Đánh giá CLN thường dựa trên dữ liệu quan trắc nồng độ và tải lượng chất ô nhiễm [2]. Tuy nhiên, việc dựa trên các thông số riêng lẻ tạo nên những rào cản trong nhận định tổng quát CLN theo không gian và thời gian. Do vậy, chỉ số CLN (Water Quality Index-WQI) được xây dựng và ứng dụng lần đầu tiên tại Mỹ (1965-1970), sau đó được nghiên cứu và phát triển ở nhiều quốc gia trên thế giới [3-5] nhằm cung cấp thông tin chung về CLN cho các nhà cung cấp và cộng đồng [6]; nghiên cứu ảnh hưởng của các chính sách và chương trình liên quan đến chất lượng môi trường [7]; so sánh CLN giữa các nguồn và các vị trí khác nhau [8]; hỗ trợ các nhà hoạch định chính sách và cộng đồng giảm thiểu các đánh giá chủ quan và thiên vị [9].

Phân tích tổng quan 30 loại WQI hiện có theo trình tự bốn bước xây dựng chỉ số WQI (lựa chọn thông số, chuyển đổi chỉ số phụ, thiết lập trọng số, tính toán chỉ số tổng hợp) [10] cho thấy: không có phương pháp chung nhất để tính toán WQI; có thể tiếp cận cả 4 bước hoặc ít hơn khi thiết lập; không có phương pháp đảm bảo tuyệt đối khách quan và độ tin cậy. 
Đáng lưu ý khi chỉ có chỉ số WQI của Canada-CCME (Canadian Council of Ministers of the Environment) thực hiện phân tích độ nhạy cho cả 4 bước nhằm giảm thiểu tính không chắc chắn của kết quả đầu ra, trong khi các phương pháp khác thực hiện kiểm nghiệm ít hơn, hoặc sử dụng các phương pháp khác nhau trong quá trình thiết lập, chẳng hạn lựa chọn thông số và phương pháp tổng hợp khác nhau, số lượng thông số và phương pháp xác định trọng số khác nhau. Các nghiên cứu cũng chỉ ra rằng mỗi lưu vực sông nên được đánh giá bởi một bộ thông số riêng biệt cũng như không thể so sánh WQI giữa các lưu vực sông khác nhau khi khác nhau các thông số cấu thành.

Vùng bờ TpHCM bao gồm toàn bộ diện tích đất liền của huyện Cần Giờ và vùng biển ven bờ có ranh giới ngoài cách mép bờ 06 hải lý (khoảng $11 \mathrm{~km}$ ) từ vịnh Gành Rái đến cửa Soài Rạp, có vai trò đặc biệt quan trọng đối với sự phát triển của thành phố. Tuy vậy, sự tăng trưởng kinh tế và gia tăng dân số nhanh chóng dọc theo lưu vực sông Sài Gòn-Đồng Nai ngày càng tạo sức ép đối với nguồn nước mặt nơi đây. Do đó, nghiên cứu nhằm mục tiêu đánh giá diễn biến và hiện trạng chất lượng nước mặt vùng bờ TpHCM giai đoạn 2016-2019, đóng góp quan trọng cho việc nhận định, dự báo xu thế biến đồi CLN trong tương lai, phục vụ hoạch định các giải pháp quản lý tương thích.

\section{Phương pháp nghiên cứu}

\subsection{Phuoong pháp lấy mẫu và phân tích mẫu}

a) Vị trí lấy mẫu: Phạm vi đánh giá diễn biến chất lượng nước mặt là vùng bờ $\mathrm{Tp}$.HCM (Hình 1 ), bao gồm toàn bộ diện tích đất liền của huyện Cần Giờ và vùng biển ven bờ có ranh giới ngoài cách mép bờ 6 hải lý (khoảng $11 \mathrm{~km}$ ) từ vịnh Gành Rái đến cửa Soài Rạp.

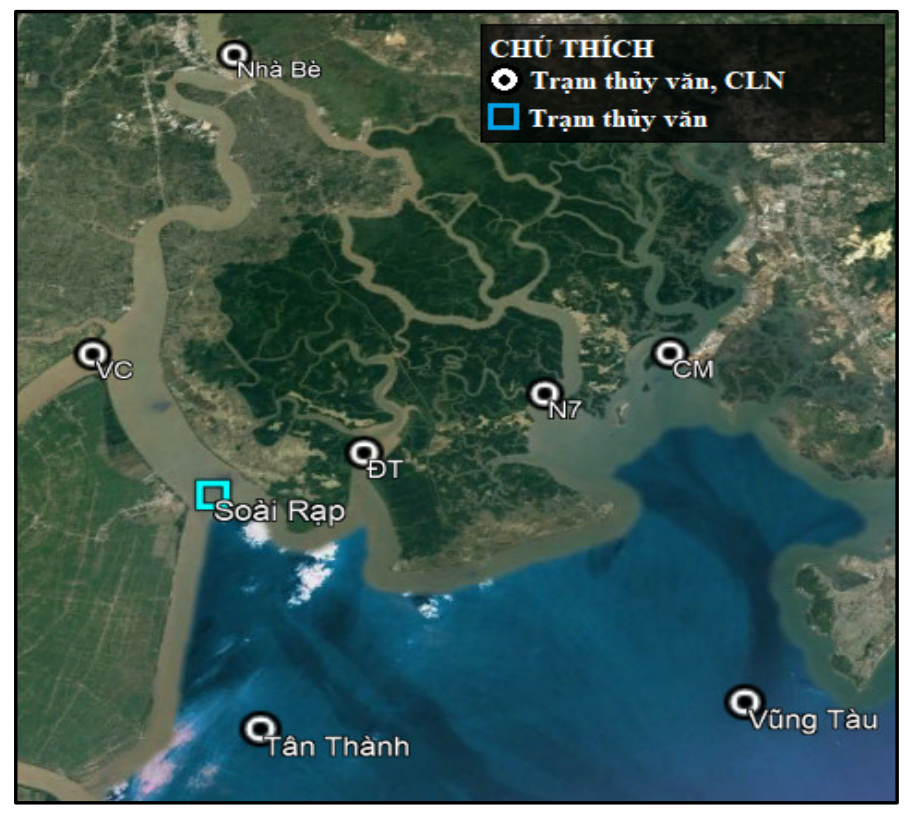

\begin{tabular}{ccc}
\hline Trạm & $\mathbf{X}$ & $\mathbf{Y}$ \\
\hline NB & 10.6803 & 106.7697 \\
VC & 10.48829 & 106.7285 \\
SR & 10.41306 & 106.7963 \\
ĐT & 10.43567 & 106.8607 \\
N7 & 10.47176 & 106.9404 \\
CM & 10.49704 & 106.9969 \\
TT & 10.28385 & 106.8311 \\
VT & 10.30641 & 107.0344 \\
\hline
\end{tabular}

Hình 1. Phạm vi nghiên cứu và vị trí quan trắc CLN liên tục (mỗi giờ).

Đới bờ ở Cần Giờ (gồm phần đất liền và vùng biển ven bờ) là khu vực đồng thời chịu ảnh hưởng của chế độ thủy văn sông Đồng Nai và chế độ hải văn Biển Đông với chế độ bán nhật triều-hàng ngày có 2 lần nước lên và 2 lần nước xuống, tốc độ dòng triều khá lớn làm cho môi trường vùng đất ngập nước Cần Giờ luôn bị xáo trộn, dẫn đến sự đồng nhất tương đối của môi trường nước mặt và nước biển ven bờ. Vì vậy, chất lượng nước biển ven bờ (NBVB) về cơ bản rất ít thay đổi theo phương song song với mép bờ (Long Hoà-Cần Thạnh), không cần quá nhiều điểm quan trắc ở khu vực này. Ngược lại, do quá trình tương tác sông biển, chất lượng môi trường nước biển ven bờ Cần Giờ thay đổi đáng kể theo hướng Tây 
Bắc-Đông Nam: từ các sông nội đồng, đến các cửa sông, mở rộng ra khu vực nước biển ven bờ (cách mép bờ 3 hải lý, khoảng $5.5 \mathrm{~km}$ ) và xa dần về phía biển Đông (cách mép bờ 6 hải lý) được xem là ranh giới kết thúc những dòng phù sa của hệ thống sông Đồng Nai. Theo đó, vị trí lấy mẫu đánh giá CLN được mô tả ở Hình 2 và Bảng 1 .

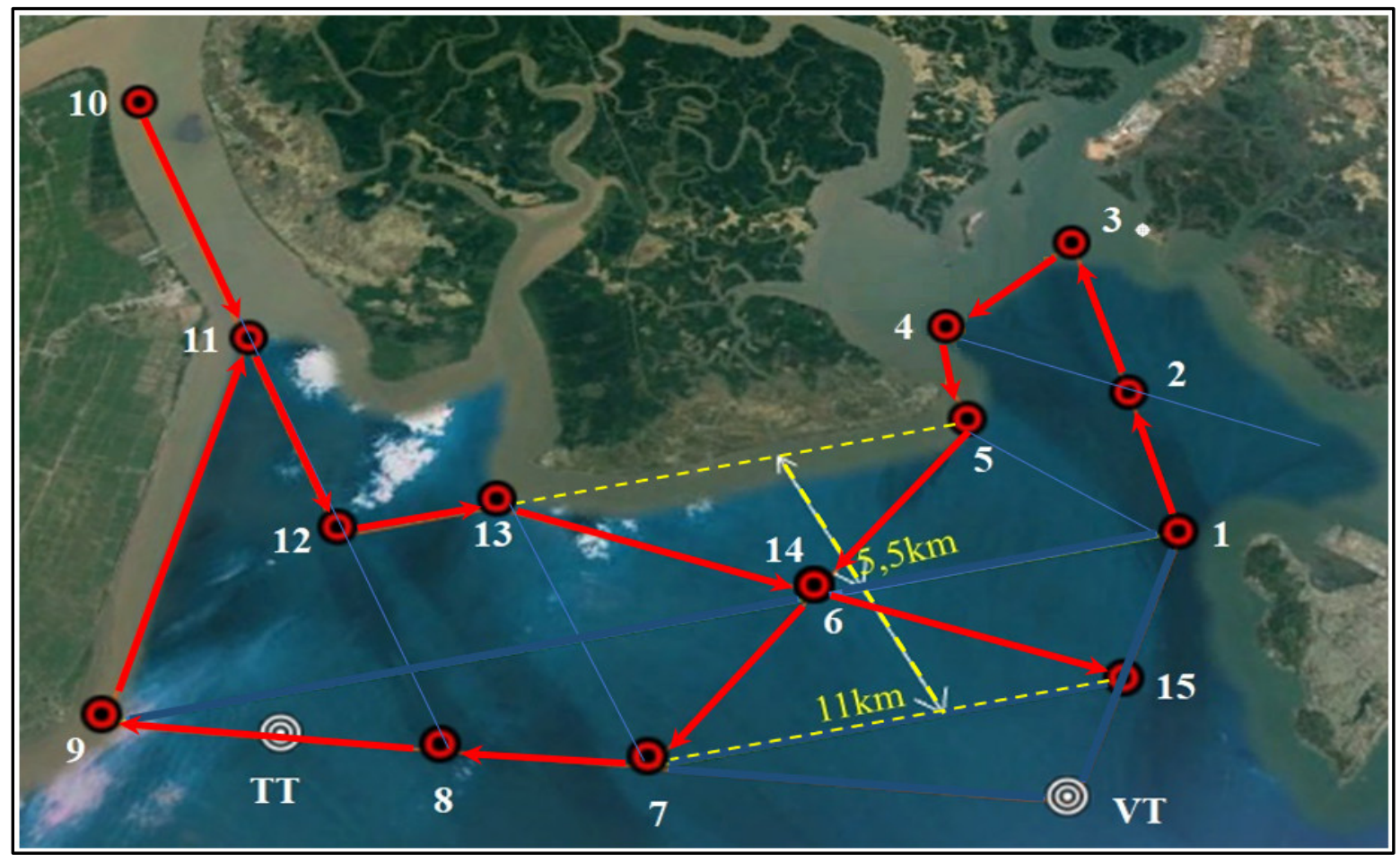

\begin{tabular}{ccc}
\hline & $\mathbf{X}$ & $\mathbf{Y}$ \\
\hline $\mathbf{1}$ & 10.38690 & 107.0448 \\
$\mathbf{2}$ & 10.41715 & 107.0350 \\
$\mathbf{3}$ & 10.46784 & 107.0047 \\
$\mathbf{4}$ & 10.45004 & 106.9580 \\
$\mathbf{5}$ & 10.40211 & 106.9922 \\
\hline
\end{tabular}

\begin{tabular}{ccc}
\hline & $\mathbf{X}$ & $\mathbf{Y}$ \\
\hline $\mathbf{6}$ & 10.34754 & 106.9552 \\
$\mathbf{7}$ & 10.30180 & 106.9288 \\
$\mathbf{8}$ & 10.28946 & 106.8714 \\
$\mathbf{9}$ & 10.28346 & 106.7987 \\
$\mathbf{1 0}$ & 10.47377 & 106.7510 \\
\hline
\end{tabular}

\begin{tabular}{ccc}
\hline & $\mathbf{X}$ & $\mathbf{Y}$ \\
\hline $\mathbf{1 1}$ & 10.40624 & 106.7973 \\
$\mathbf{1 2}$ & 10.34588 & 106.8359 \\
$\mathbf{1 3}$ & 10.36026 & 106.8762 \\
$\mathbf{1 4}$ & 10.34754 & 106.9552 \\
$\mathbf{1 5}$ & 10.33610 & 107.0360 \\
\hline
\end{tabular}

Hình 2. Vị trí lấy mẫu nước biển ven bờ.

Bảng 1. Mô tả các vị trí lấy mẫu chất lượng nước mặt.

\begin{tabular}{|c|c|c|c|}
\hline Phạm vi & Vị trí & Khu vụcc & Mô tả \\
\hline \multirow{6}{*}{$\begin{array}{l}\text { Nước mặt } \\
\text { lục địa }\end{array}$} & NB & Sông Nhà Bè & $\begin{array}{l}\text { Đánh giá CLN hạ lưu sông Nhà Bè trước khi đổ vào } \\
\text { huyện Cần Giờ }\end{array}$ \\
\hline & $\mathrm{VC}$ & Sông Vàm Cỏ & $\begin{array}{l}\text { Đánh giá CLN sông Vàm Cỏ trước khi đổ vào huyện } \\
\text { Cần Giờ tại hợp lưu với sông Soài Rạp }\end{array}$ \\
\hline & 10,11 & Sông Soài Rạp & \multirow{2}{*}{$\begin{array}{l}\text { Đánh giá CLN các sông chính nội vi huyện Cần Giờ } \\
\text { trước khi đồ vào vịnh Đồng Tranh }\end{array}$} \\
\hline & ĐT & Sông Đồng Tranh & \\
\hline & N7 & Sông Lòng Tàu & \multirow{2}{*}{$\begin{array}{l}\text { Đánh giá CLN các sông chính nội vi huyện Cần Giờ } \\
\text { trước khi đồ vào vịnh Gành Rái }\end{array}$} \\
\hline & $\mathrm{CM}$ & Sông Thị Vải & \\
\hline \multirow{3}{*}{$\begin{array}{l}\text { Nước biển } \\
\text { ven bờ }\end{array}$} & $1-5$ & Vịnh Gành Rái & Đánh giá CLN vịnh Gành Rái \\
\hline & $9,11-13$ & Vịnh Đồng Tranh & Đánh giá CLN vịnh Đồng Tranh \\
\hline & $5-8,13-15$ & Vùng biển ven bờ & Đánh giá chất lượng NBVB TpHCM \\
\hline
\end{tabular}


b) Thời gian lấy mẫu: 20-22/4/2019 (mùa khô)

c) Phân tích mẫu: 09 thông số bao gồm pH, DO, BOD, $\mathrm{COD}\left(\mathrm{KMnO}_{4}\right), \mathrm{N}-\mathrm{NH}_{4}^{+}, \mathrm{N}-$ $\mathrm{NO}_{3}{ }^{-}, \mathrm{P}-\mathrm{PO}_{4}{ }^{3-}$, Coliform, TSS.

d) Phương pháp lấy mẫu nước: Áp dụng TCVN 5998:1995 (ISO 5667-9:1992) đối với mẫu nước biển và TCVN 6663-6:2008 (ISO 5667-6:2005) đối với mẫu nước sông.

e) Phương pháp bảo quản mẫu: áp dụng TCVN 5993:1995 (ISO 5667-3).

f) Các quy chuẩn tham chiếu: QCVN 08:2015/BTNMTvề chất lượng nước mặt lục địa

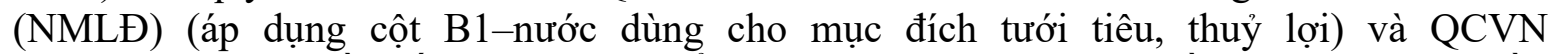
10:2015/BTNMT về chất lượng nước biển (áp dụng cho vùng nuôi trồng thuỷ sản, bảo tồn thuỷ sinh ven bờ).

\subsection{Phương pháp tính toán chỉ số chất lượng nước}

CLN vùng bờ TpHCM được đánh giá tổng hợp bằng chỉ số WQI (Bảng 3-4). Diễn biến CLN giai đoạn 2016-2019 được đánh giá trên cơ sở dữ liệu quan trắc định kì của Trung tâm Quan trắc và Phân tích Môi trường (Sở Tài nguyên và Môi trường TpHCM). Toạ độ các trạm quan trắc được trình bày ở Bảng 2 .

Bảng 2. Toạ độ các trạm quan trắc nước mặt trong phạm vi nghiên cứu.

\begin{tabular}{|c|c|c|c|c|}
\hline Khu vụ̣c & Trạm & Ký hiệu & $\mathbf{X}$ & $\mathbf{Y}$ \\
\hline \multirow{7}{*}{$\begin{array}{l}\text { Nước mặt } \\
\text { lục địa } \\
(1-7)\end{array}$} & 1. Nhà Bè & NB & 1181376,54 & 610844,32 \\
\hline & 2. Tam Thôn Hiệp & TTH & 1173326,10 & 621959,92 \\
\hline & 3.Vàm Sát & VS & 1165407,99 & 608467,14 \\
\hline & 4.Vàm Cỏ & $\mathrm{VC}$ & 1157697,90 & 604458,64 \\
\hline & 5.Đồng Tranh & ĐT & 1154643,08 & 621048,55 \\
\hline & 6.Ngã Bảy & N7 & 1161689,90 & 631305,55 \\
\hline & 7.Cái Mép & $\mathrm{CM}$ & 1164456,83 & 638719,84 \\
\hline \multirow{7}{*}{$\begin{array}{c}\text { Nước biển } \\
\text { ven bờ } \\
(8-14)\end{array}$} & 8.Cửa Đồng Tranh & C.ĐT & 1151767,77 & 621381,62 \\
\hline & 9.Cửa Lòng Tàu & C.LT & 1158220,81 & 629844,33 \\
\hline & 10.Cửa Cái Mép & C.CM & 1160081,41 & 635807,34 \\
\hline & 11.Công viên Cần Thạnh & $\mathrm{CT}$ & 1151811,73 & 633856,50 \\
\hline & 12.Khu du lịch 30 Tháng 4 & $30 / 4$ & 1150590,31 & 632151,56 \\
\hline & 13.Bãi Đồng Hòa & ĐH & 1146718,97 & 624794,52 \\
\hline & 14.KDL Hòn Ngọc Phương Nam & HNPN & 1147769,78 & 624769,50 \\
\hline
\end{tabular}

Chỉ số WQI-VN tính toán theo Quyết định 1460/QĐ-TCMT của Tổng cục Môi trường ngày 12/11/2019, chỉ áp dụng đối với NMLĐ (hiện chưa có hướng dẫn đối với NBVB). Để đánh giá đồng bộ trên toàn phạm vi nghiên cứu (gồm cả NMLĐ và NBVB), áp dụng chỉ số CCME - đề xuất bởi Hội đồng Bộ trưởng Môi trường Canada (Canadian Council of Ministers of Environment).

$$
\begin{array}{ll}
\mathrm{CCME}=100-\left(\frac{\sqrt{\mathrm{F}_{1}^{2}+\mathrm{F}_{2}^{2}+\mathrm{F}_{3}^{2}}}{1.732}\right) & \mathrm{F} 3=\frac{N S E}{0,01 N S E+0,01} \\
\mathrm{~F} 1=\frac{\text { Số thông số không đạt }}{\text { Tổng số thông số }} \times 100 & N S E=\frac{\sum_{i=1}^{n} \text { Độ lệch_i } i}{\text { Tổng số giá } t r i ̣ ~}-1 \\
\mathrm{~F} 2=\frac{\text { Số giá trị không đạt }}{\text { Tổng số giá trị }} \times 100 & \text { Độ lệch_i } i=\frac{\text { Giá trị vượt chuẩn_i }}{\text { Giá trị giới hạn_i }}-1
\end{array}
$$


Trong đó F1 (phạm vi) là tỉ lệ giữa số thông số CLN không đạt chuẩn với tổng số các thông số được quan trắc; F2 (tần số) là số lần không đạt chuẩn với tổng số các kết quả quan trắc của tất cả các thông số; F3 (biên độ) là độ lớn của thông số không đạt chuẩn so với giá trị quy chuẩn của thông số đó; NSE là độ lệch tổng cộng chuẩn hóa; Độ lệch_i được tính toán khi nồng độ của thông số không đạt quy chuẩn tương ứng; 1,732 là độ dài cực đại của vectơ tổ hợp giữa $F 1, F 2$ và $F 3$.

Bảng 3. Tổ hợp các thông số tính toán chỉ số WQI: (a) Các chỉ số CLN và mục đích sử dụng.

\begin{tabular}{|c|c|c|c|c|c|c|c|}
\hline STT & Mục đích & Phạm vi & Mô tả dũ̃ liệu & Thời gian & Co'sở & Thông số CLN & Ký hiệu \\
\hline 1 & $\begin{array}{l}\text { Đánh giá hiện } \\
\text { trạng CLN vùng } \\
\text { bờ TpHCM theo } \\
\text { CCME }\end{array}$ & $\begin{array}{l}\text { Từ s.Nhà } \\
\text { Bè ra vùng } \\
\text { biển cách } \\
\text { bờ } 6 \text { hải lý }\end{array}$ & $\begin{array}{l}22 \text { vị trí lấy } \\
\text { mẫu (cả NMLĐ } \\
\text { và NBVB) }\end{array}$ & 4/ 2019 & CCME & $\begin{array}{l}9 \text { thông số CLN đã } \\
\text { đề cập thuộc } \\
\text { nghiên cứu này }\end{array}$ & $\begin{array}{c}\text { WQI. } \\
1\end{array}$ \\
\hline 2 & $\begin{array}{l}\text { Đánh giá diễn } \\
\text { biến CLN vùng } \\
\text { bờ TpHCM theo } \\
\text { CCME }\end{array}$ & $\begin{array}{l}\text { Từ s.Nhà } \\
\text { Bè ra vùng } \\
\text { biển ven bờ }\end{array}$ & $\begin{array}{l}14 \text { trạm của Sở } \\
\text { TNMT-HCM, } \\
\text { gồm } 07 \text { trạm } \\
\text { NMLĐ và } 07 \\
\text { trạm NBVB }\end{array}$ & $\begin{array}{c}2016- \\
2019\end{array}$ & CCME & $\begin{array}{l}8 \text { thông số } \text { CLN } \\
\text { quan trắc dồng } \\
\text { thời cho cả } \\
\text { NMLĐ và NBVB }\end{array}$ & $\begin{array}{c}\text { WQI. } \\
5\end{array}$ \\
\hline
\end{tabular}

3 So sánh CLN theo các chỉ số CLN

3.1 Theo QĐ1460 bằng 02 tổ hợp dĩ liệu

\begin{tabular}{|c|c|c|c|c|c|c|c|}
\hline & \multirow[t]{2}{*}{ WQI.2 vs. WQI.7 } & \multirow{2}{*}{$\begin{array}{l}\text { Từ sông } \\
\text { Nhà Bè ra } \\
\text { vùng cửa } \\
\text { sông huyện } \\
\text { Cần Giờ }\end{array}$} & \multirow[t]{2}{*}{$\begin{array}{l}7 \text { trạm quan } \\
\text { trắc NMLĐ của } \\
\text { Sở TNMT }\end{array}$} & \multirow[t]{2}{*}{$\begin{array}{c}12 / 2017- \\
5 / 2018\end{array}$} & \multirow[t]{2}{*}{1460} & $\begin{array}{l}7 \text { thông số như } \\
\text { WQI.1 ngoại trừ } \\
\mathrm{NO}_{3}-\mathrm{N} \text { (do Sở } \\
\mathrm{TNMT}^{2} \text { không } \\
\text { phân tích), TSS } \\
\text { (theo QĐ1460) }\end{array}$ & $\begin{array}{c}\text { WQI. } \\
7\end{array}$ \\
\hline & & & & & & $\begin{array}{l}12 \text { thông số - khai } \\
\text { thác tối đa dữ liệu } \\
\text { theo QĐ1460 }\end{array}$ & $\begin{array}{c}\text { WQI. } \\
2\end{array}$ \\
\hline \multirow[t]{2}{*}{3.2} & \multicolumn{7}{|c|}{ Theo $Q Đ 1460$ và $C C M E$} \\
\hline & $\begin{array}{l}\text { Trường hợp tối đa } \\
\text { dữ liệu } \\
\text { WQI.2 vs. WQI.3 }\end{array}$ & $\begin{array}{l}\text { Từ sông } \\
\text { Nhà Bè ra } \\
\text { vùng cửa } \\
\text { sông huyện } \\
\text { Cần Giờ }\end{array}$ & $\begin{array}{l}7 \text { trạm quan } \\
\text { trắc NMLĐ của } \\
\text { Sở TNMT }\end{array}$ & $\begin{array}{r}12 / 2017 \\
-5 / 2018\end{array}$ & CCME & $\begin{array}{l}12 \text { thông số - khai } \\
\text { thác tối đa dữ liệu } \\
\text { theo QĐ1460 }\end{array}$ & $\begin{array}{c}\text { WQI. } \\
3\end{array}$ \\
\hline \multirow[t]{3}{*}{3.3} & \multicolumn{7}{|c|}{ Theo CCME bằng 02 tổ hơp dũ liệu } \\
\hline & WQI.5 vs. WQI.4 & $\begin{array}{l}\text { Từ sông } \\
\text { Nhà Bè ra } \\
\text { vùng cửa } \\
\text { sông huyện } \\
\text { Cần Giờ }\end{array}$ & $\begin{array}{l}7 \text { trạm quan } \\
\text { trắc NMLĐ của } \\
\text { Sở TNMT }\end{array}$ & $\begin{array}{r}12 / 2017 \\
-5 / 2018\end{array}$ & CCME & $\begin{array}{l}15 \text { thông số - khai } \\
\text { thác tối đa và thích } \\
\text { hợp dữ liệu quan } \\
\text { trắc }\end{array}$ & $\begin{array}{c}\text { WQI. } \\
4\end{array}$ \\
\hline & WQI.5 vs. WQI.6 & $\begin{array}{l}\text { Vùng biển } \\
\text { ven bờ } \\
\text { TpHCM }\end{array}$ & $\begin{array}{l}7 \text { trạm quan } \\
\text { trắc NBVB của } \\
\text { Sở TNMT }\end{array}$ & $\begin{array}{r}12 / 2017 \\
-5 / 2018\end{array}$ & CCME & $\begin{array}{l}10 \text { thông số - khai } \\
\text { thác tối đa và thích } \\
\text { hợp dữ liệu quan } \\
\text { tắc }\end{array}$ & $\begin{array}{c}\text { WQI. } \\
6\end{array}$ \\
\hline
\end{tabular}


Bảng 3. Tổ hợp các thông số tính toán chỉ số WQI: (b) Mô tả thành phần của các chỉ số WQI.

\begin{tabular}{|c|c|c|c|c|c|c|c|c|}
\hline \multirow{2}{*}{ Thông số } & WQI.1 & WQI.2 & WQI.3 & WQI.4 & WQI.5 & WQI.6 & WQI.7 & WQI.8 \\
\hline & CCME & 1460 & CCME & CCME & CCME & CCME & 1460 & 1460 \\
\hline $\mathrm{pH}$ & $\mathrm{X}$ & $\mathrm{x}$ & $\mathrm{x}$ & $\mathrm{x}$ & $\mathrm{x}$ & $\mathrm{X}$ & $\mathrm{x}$ & $\mathrm{x}$ \\
\hline $\mathrm{DO}$ & $\mathrm{x}$ & $\mathrm{x}$ & $x$ & $\mathrm{x}$ & $\mathrm{x}$ & $\mathrm{x}$ & $\mathrm{x}$ & $\mathrm{x}$ \\
\hline BOD & $\mathrm{x}$ & $\mathrm{x}$ & $\mathrm{x}$ & $\mathrm{x}$ & & & $\mathrm{x}$ & $\mathrm{x}$ \\
\hline COD & $\mathrm{x}$ & $\mathrm{x}$ & $x$ & $\mathrm{x}$ & & & $\mathrm{x}$ & $x$ \\
\hline $\mathrm{NH}_{4}{ }^{+}-\mathrm{N}$ & $\mathrm{x}$ & $\mathrm{x}$ & $\mathrm{x}$ & $\mathrm{x}$ & $\mathrm{x}$ & $\mathrm{x}$ & $\mathrm{x}$ & $\mathrm{x}$ \\
\hline $\mathrm{NO}_{3}{ }^{-}-\mathrm{N}$ & $\mathrm{x}$ & & & & & & & $\mathrm{x}$ \\
\hline $\mathrm{PO}_{4}{ }^{3-}-\mathrm{P}$ & $\mathrm{x}$ & $\mathrm{x}$ & $\mathrm{x}$ & $\mathrm{x}$ & & & $\mathrm{x}$ & $x$ \\
\hline TSS & $\mathrm{x}$ & & & & & & & \\
\hline Coliform & $\mathrm{x}$ & $\mathrm{X}$ & $x$ & $\mathrm{x}$ & $\mathrm{x}$ & $\mathrm{X}$ & $\mathrm{x}$ & $\mathrm{x}$ \\
\hline E.Coli & & $\mathrm{x}$ & $x$ & $\mathrm{x}$ & & & & \\
\hline $\mathrm{Pb}$ & & $\mathrm{x}$ & $x$ & $\mathrm{x}$ & $\mathrm{x}$ & $\mathrm{x}$ & & \\
\hline $\mathrm{Cd}$ & & $\mathrm{x}$ & $\mathrm{x}$ & $\mathrm{x}$ & $\mathrm{x}$ & $\mathrm{X}$ & & \\
\hline $\mathrm{Cu}$ & & $\mathrm{x}$ & $x$ & $\mathrm{X}$ & $\mathrm{x}$ & $\mathrm{x}$ & & \\
\hline $\mathrm{Fe}$ & & & & $\mathrm{x}$ & & & & \\
\hline $\mathrm{Zn}$ & & $\mathrm{x}$ & $\mathrm{x}$ & $\mathrm{x}$ & & & & \\
\hline $\mathrm{Mn}$ & & & & $\mathrm{x}$ & & & & \\
\hline As & & & & & & $\mathrm{x}$ & & \\
\hline $\mathrm{Hg}$ & & & & & $\mathrm{x}$ & $\mathrm{x}$ & & \\
\hline Dầu & & & & $\mathrm{x}$ & & $\mathrm{X}$ & & \\
\hline Tổng cộng & 9 & 12 & 12 & 15 & 8 & 10 & 7 & 8 \\
\hline
\end{tabular}

Bảng 4. Quy ước về giá trị (chỉ số), màu sắc và mức CLN.

\begin{tabular}{|c|c|c|c|c|c|}
\hline WQI & CLN & Khuyến nghị & CCME & CLN & Khuyến nghị \\
\hline $91-100$ & Rất tốt & $\begin{array}{l}\text { Sử dụng tốt cho mục đích cấp } \\
\text { nước sinh hoạt }\end{array}$ & 95-100 & Rất tốt & $\begin{array}{l}\text { Không có mối đe dọa hoặc } \\
\text { suy yểu về nguồn nước }\end{array}$ \\
\hline $76-90$ & Tốt & $\begin{array}{l}\text { Cấp nước sinh hoạt nhưng cần } \\
\text { biện pháp xử lý phù hợp }\end{array}$ & $80-94$ & Tốt & $\begin{array}{l}\text { Nguồn nước được bảo vệ } \\
\text { tương đối tốt }\end{array}$ \\
\hline $51-75$ & $\begin{array}{l}\text { Trung } \\
\text { bình }\end{array}$ & $\begin{array}{l}\text { Tưới tiêu và các mục đích } \\
\text { tương đương khác }\end{array}$ & $65-79$ & Khá & $\begin{array}{l}\text { Nguồn nước đôi khi bị đe } \\
\text { dọa hoặc suy yếu }\end{array}$ \\
\hline $26-50$ & Kém & $\begin{array}{l}\text { Giao thông thủy và các mục } \\
\text { đích tương đương khác }\end{array}$ & $45-64$ & $\begin{array}{l}\text { Trung } \\
\text { bình }\end{array}$ & $\begin{array}{l}\text { Nguồn nước thường xuyên } \\
\text { bị đe dọa hoặc suy yếu }\end{array}$ \\
\hline $10-25$ & $\begin{array}{l}\text { Ô nhiễm } \\
\text { nặng }\end{array}$ & $\begin{array}{l}\text { Ô nhiễm nặng, cần các biện } \\
\text { pháp xử lý trong tương lai }\end{array}$ & \multirow{2}{*}{$0-44$} & \multirow{2}{*}{ Xấu } & \multirow{2}{*}{$\begin{array}{l}\text { Nguồn nước đang bị bị đe } \\
\text { dọa hoặc suy yếu }\end{array}$} \\
\hline$<10$ & $\begin{array}{l}\text { Ô nhiễm } \\
\text { rất nặng }\end{array}$ & $\begin{array}{l}\text { Nước nhiễm độc, cần có biện } \\
\text { pháp khắc phục, xử lý }\end{array}$ & & & \\
\hline
\end{tabular}

\section{Kết quả và thảo luận}

\subsection{Hiện trạng CLN vùng bò̀ TpHCM vào mùa khô 2019}

Thông số CLN đáng quan tâm: kết quả phân tích cho thấy hầu hết các thông số CLN tại vùng bờ TpHCM đáp ứng quy chuẩn cho phép (QCVN:08-2015 và $\mathrm{QCVN}: 10-2015)$. Tuy vậy, dấu hiệu ô nhiễm được ghi nhận ở một số vị trí như: chì $(\mathrm{Pb})$, vượt chuẩn từ 1,2-1,4 lần tại hạ lưu sông Vàm Cỏ và sông Lòng Tàu; chất rắn lơ lửng (TSS), hiện diện ở mức cao (vuợt chuẩn từ 3-7 lần ở hạ lưu các sông và 3-4 lần ở khu vực ven bờ).

Xu hướng lan truyền ô nhiễm: hàm lượng chất ô nhiễm giảm dần ra biển-có thể được giải thích bởi phân bố các hoạt động dân sinh cũng như việc mở rộng không gian trao đổi nước, lan truyền, pha loãng ra vùng cửa sông, ven biển (Hình 3). Khu vực đáng quan tâmcó CLN thấp nhất trong phạm vi nghiên cứu ghi nhận tại hợp lưu của sông Vàm Cỏ và sông 
Soài Rạp đến cửa sông Soài Rạp; hạ lưu sông Đồng Tranh. CLN tại vịnh Đồng Tranh, vịnh Gành Rái và khu vực ven biển (cách bờ 3-6 hải lý) hiện ở mức tốt.

Ảnh hưởng của thuỷ triều: kết quả phân tích CLN thuộc nghiên cứu này, kết hợp với dữ liệu quan trắc trong 2 điều kiện triều khác nhau của mỗi tháng-khai thác từ Trung tâm Quan trắc và phân tích môi trường-Sở TN\&MT TpHCM chỉ ra nồng độ các chất trong thời điểm triều rút cao hơn lúc triều lên, dễ nhận thấy tại khu vực nội đồng (Hình 4, Bảng 5). Điều này có thể được giải thích bởi khi nước lên, phần nào pha loãng nồng độ chất ô nhiễm trong sông, ngược lại, khi nước rút, chất ô nhiễm từ các sông rạch nội đồng sẽ bị lôi cuốn, thoát ra dòng chính và làm giảm CLN tại đây.
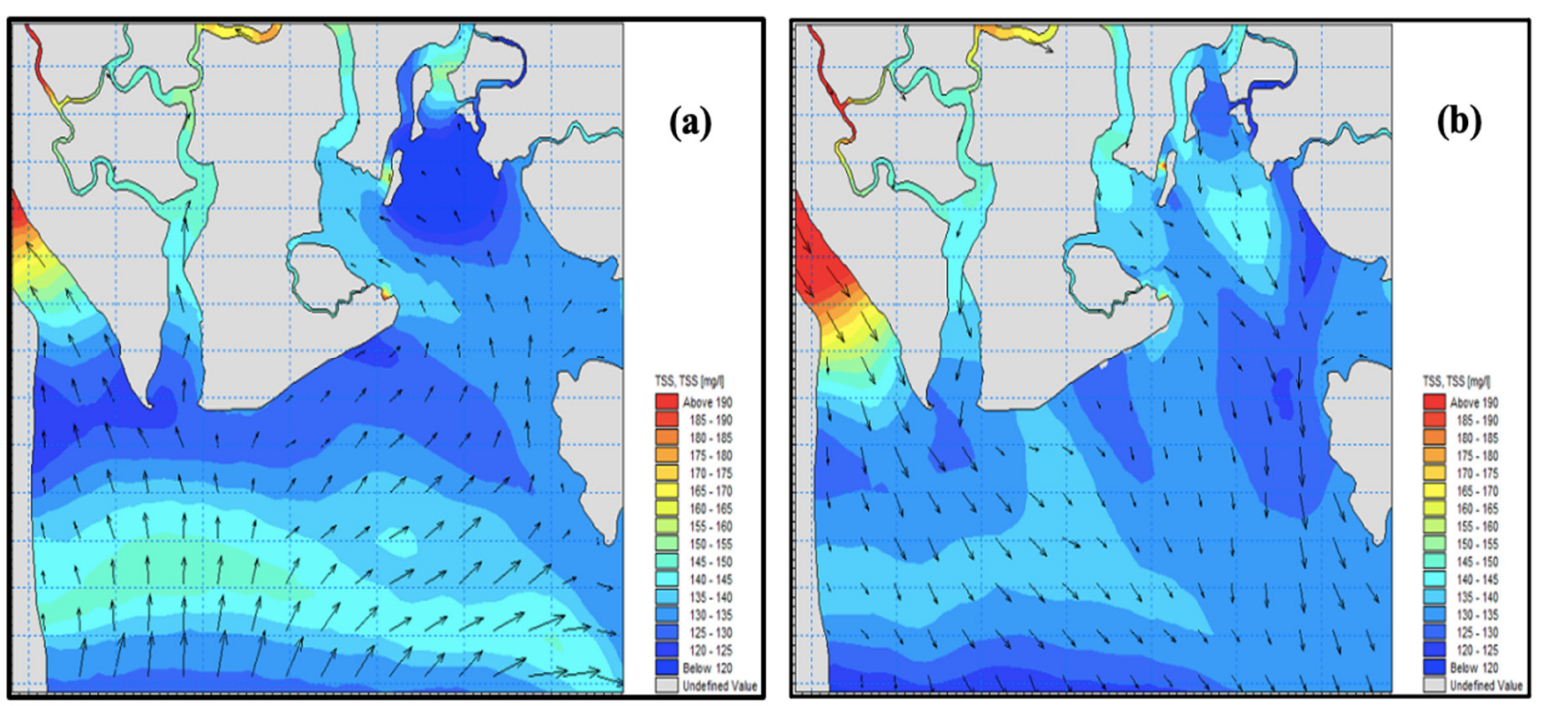

Hình 3. Hàm lượng TSS tại vùng bờ TpHCM vào tháng 4/2019: (a) Triều lên; (b) Triều rút.
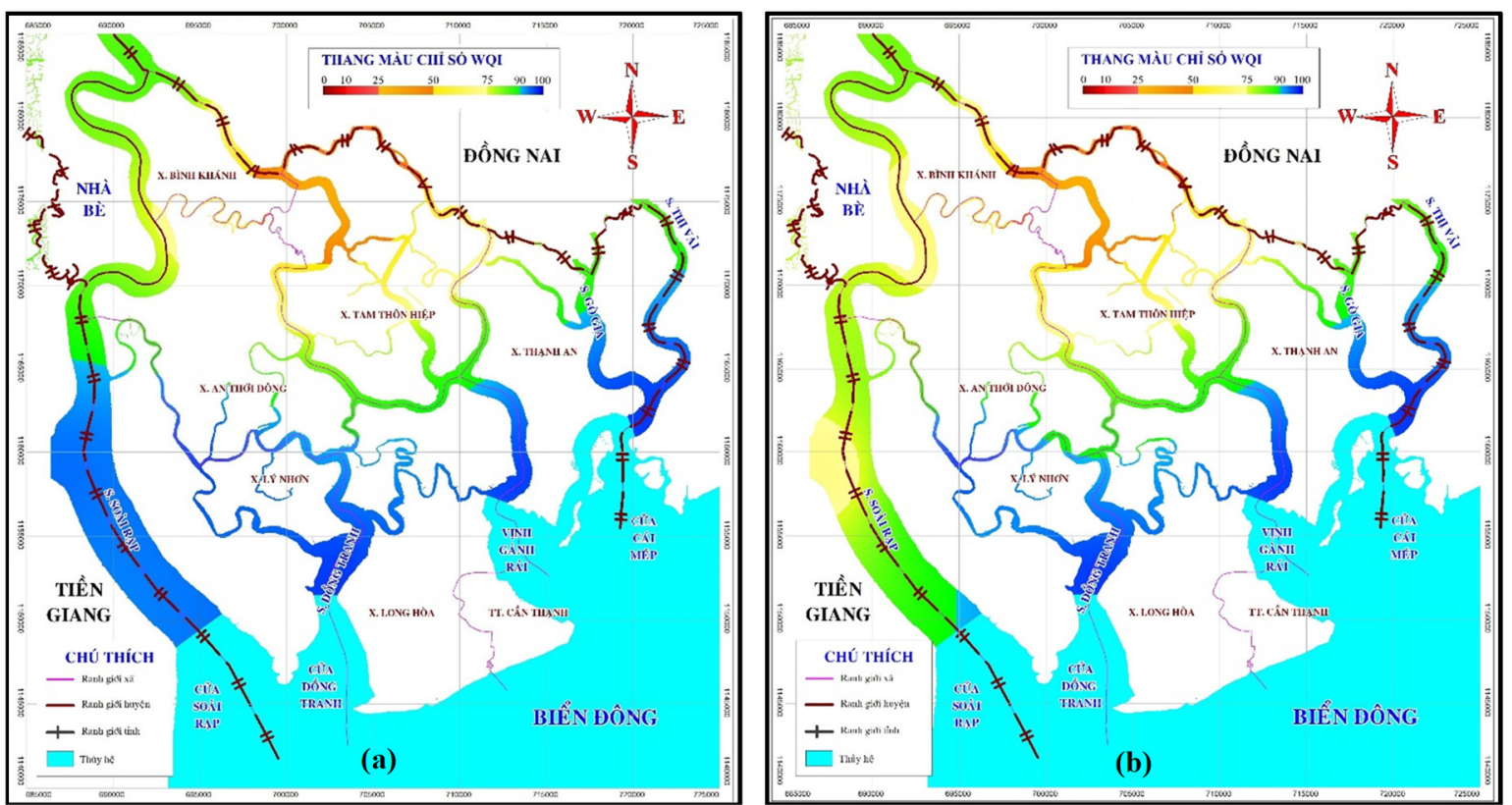

Hình 4. Chỉ số chất lượng NMLĐ vùng bờ-Tháng 4/2019 (WQI.8): (a) Triều lên; (b) Triều rút. 
Bảng 5. Chất lượng nước mặt vùng bờ TpHCM- Mùa khô 2019: (a) Nước biển ven bờ.

\begin{tabular}{|c|c|c|c|c|c|c|c|c|c|c|c|c|c|}
\hline \multirow[t]{2}{*}{ Khu vực } & \multirow[t]{2}{*}{ Trạm } & \multirow[t]{2}{*}{ Triều } & \multirow{3}{*}{$\begin{array}{c}\text { pH } \\
6,5- \\
8,5\end{array}$} & DO & BOD & COD & $\mathrm{NH}_{4}{ }^{+}-\mathrm{N}$ & $\mathrm{NO}_{3}{ }^{-}-\mathrm{N}$ & $\mathrm{PO}_{4}{ }^{3-}-\mathrm{P}$ & \multirow{2}{*}{$\begin{array}{c}\text { Coliform } \\
\mathrm{MNP} / \\
100 \mathrm{~mL} \\
\end{array}$} & \multicolumn{2}{|c|}{ TSS } & \multirow{3}{*}{ WQI.1 } \\
\hline & & & & \multicolumn{6}{|c|}{$\mathrm{mg} / \mathrm{L}$} & & $\mathrm{mg} / \mathrm{L}$ & $\%$ & \\
\hline \multicolumn{3}{|c|}{ QCVN10:2015-NTTS } & & $\geq 5$ & - & - & 0,1 & - & 0,2 & 1000 & 50 & VC & \\
\hline \multirow{5}{*}{$\begin{array}{c}\text { Vịnh } \\
\text { Gành Rái }\end{array}$} & 01 & NL & 8,06 & 5,2 & 2,6 & 6,4 & 0,03 & 0,08 & 0,02 & 90 & 79 & 158 & 90 \\
\hline & 02 & NR & 7,47 & 5,6 & 2,6 & 6,0 & 0,03 & 0,09 & 0,03 & 40 & 122 & 244 & 88 \\
\hline & 03 & NR & 7,48 & 5,7 & 2,7 & 7,0 & 0,05 & 0,10 & 0,03 & 60 & 204 & 408 & 83 \\
\hline & 04 & NR & 7,69 & 5,5 & 2,8 & 6,9 & 0,06 & 0,26 & 0,05 & 130 & 180 & 360 & 84 \\
\hline & 05 & NR & 7,70 & 5,6 & 2,7 & 6,4 & 0,04 & 0,16 & 0,06 & 120 & 180 & 360 & 84 \\
\hline \multirow{4}{*}{$\begin{array}{l}\text { Vịnh } \\
\text { Đồng } \\
\text { Tranh }\end{array}$} & 09 & NL & 7,67 & 5,1 & 2,9 & 6,8 & 0,04 & 0,23 & 0,03 & 260 & 126 & 252 & 88 \\
\hline & 11 & NL & 7,89 & 5,1 & 2,8 & 7,5 & 0,09 & 0,19 & 0,06 & 220 & 170 & 340 & 84 \\
\hline & 12 & NL & 7,84 & 5,3 & 2,7 & 6,7 & 0,06 & 0,20 & 0,04 & 30 & 118 & 236 & 88 \\
\hline & 13 & NL & 7,63 & 5,4 & 2,7 & 6,5 & 0,09 & 0,26 & 0,05 & 190 & 143 & 286 & 87 \\
\hline \multirow{9}{*}{$\begin{array}{l}\text { Vùng } \\
\text { Biển } \\
\text { Ven } \\
\text { Bờ }\end{array}$} & 06 & NR & 7,66 & 5,6 & 2,4 & 6,2 & 0,04 & 0,10 & 0,02 & 40 & 167 & 334 & 85 \\
\hline & 14 & NL & 8,21 & 5,2 & 2,5 & 6,3 & 0,04 & 0,24 & 0,04 & 90 & 158 & 316 & 87 \\
\hline & 15 & NL & 8,04 & 5,4 & 2,3 & 5,8 & 0,05 & 0,19 & 0,02 & 130 & 83 & 166 & 90 \\
\hline & 07 & NL & 7,69 & 5,4 & 2,5 & 6,0 & 0,05 & 0,12 & 0,02 & 160 & 119 & 238 & 88 \\
\hline & 08 & NL & 7,81 & 5,3 & 2,6 & 6,2 & 0,04 & 0,24 & 0,02 & 110 & 99 & 198 & 89 \\
\hline & $\mathrm{TT}$ & NR & 7,98 & 4,9 & 2,8 & 6,5 & 0,04 & 0,14 & 0,02 & 170 & 112 & 224 & 80 \\
\hline & $\mathrm{TT}$ & NL & 7,96 & 4,9 & 2,4 & 6,1 & 0,05 & 0,25 & 0,02 & 110 & 132 & 264 & 80 \\
\hline & VT & NR & 8,18 & 5,2 & 2,6 & 7,2 & 0,04 & 0,28 & 0,02 & 140 & 118 & 236 & 88 \\
\hline & VT & NL & 8,20 & 5,1 & 2,4 & 6,9 & 0,03 & 0,29 & 0,02 & 120 & 155 & 310 & 86 \\
\hline
\end{tabular}

Bảng 5. Chất lượng nước mặt vùng bờ TpHCM- Mùa khô 2019: (b) Nước mặt lục địa.

\begin{tabular}{|c|c|c|c|c|c|c|c|c|c|c|c|c|c|c|c|c|c|c|}
\hline \multirow[t]{2}{*}{ Khu vực } & \multirow[t]{2}{*}{ Trạm } & \multirow[t]{2}{*}{ Triều } & \multirow{3}{*}{$\begin{array}{c}\text { pH } \\
5,5- \\
9,0\end{array}$} & $\mathbf{P b}$ & d & $\mathrm{Cu}$ & $\mathbf{Z n}$ & DO & BOD & COD & $\mathbf{N H}_{4}{ }^{+}$ & $3^{-}$ & $\mathrm{PO}_{4}{ }^{3-}$ & \multirow{3}{*}{$\begin{array}{c}\begin{array}{c}\text { Coliform } \\
\mathrm{MNP} /\end{array} \\
100 \mathrm{~mL} \\
\mathbf{7 5 0 0} \\
\end{array}$} & \multirow{2}{*}{\multicolumn{2}{|c|}{$\begin{array}{c}\text { TSS } \\
\mathrm{mg} / \mathrm{L} \%\end{array}$}} & \multirow{3}{*}{ WQI.1 } & \multirow{3}{*}{ WQI.8 } \\
\hline & & & & \multicolumn{10}{|c|}{$\mathrm{mg} / \mathrm{L}$} & & & & & \\
\hline QCVN 08: & 2015 & 31 & & 0,05 & 0,01 & 0,5 & 1,5 & $\geq 4$ & 15 & 30 & 0,9 & 10 & 0,3 & & 50 & VC & & \\
\hline Sôn & NB & $\mathrm{NL}$ & 7,91 & - & - & - & - & 4,6 & 3,3 & 9,1 & 0,08 & 0,58 & 0,06 & 4600 & 57 & 114 & 91 & 96 \\
\hline Nhà Bè & NB & NR & 7,92 & 0,02 & $\mathrm{KPH}$ & 0,03 & 0,05 & 4,2 & 2,8 & 8,6 & 0,04 & 0,71 & 0,08 & 4600 & 132 & 264 & 87 & 98 \\
\hline S & $\mathrm{VC}$ & NL & 7,56 & - & 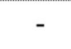 & - & - & 4,2 & 4,6 & 9,3 & 0,07 & 0,71 & 0,06 & 1700 & 101 & 202 & 89 & 97 \\
\hline Vàm Cỏ & $\mathrm{VC}$ & NR & 7,43 & 0,06 & $\mathrm{KPH}$ & 0,06 & 0,07 & 3,9 & 4,7 & 9,6 & 0,04 & 0,80 & 0,11 & 6400 & 384 & 768 & 69 & 74 \\
\hline Sông & 10 & NL & 7,79 & - & - & - & - & 5,7 & 3,1 & 7,8 & 0,08 & 0,20 & 0,06 & 240 & 204 & 408 & 83 & 86 \\
\hline Soài Rạp & 11 & $\mathrm{NL}$ & 7,89 & - & - & - & - & 5,1 & 2,8 & 7,5 & 0,09 & 0,19 & 0,06 & 220 & 170 & 340 & 4 & 0 \\
\hline S. $\oplus$ & ĐT & $\mathrm{NL}$ & 8,29 & - & - & - & - & 5,5 & 2,5 & 7,9 & 0,06 & 0,58 & 0,04 & 210 & 157 & 314 & 82 & 85 \\
\hline Tranh & ĐT & NR & 8,28 & $\mathrm{KPH}$ & $\mathrm{KPH}$ & 0,05 & 0,04 & 5,2 & 2,2 & 7,4 & 0,03 & 0,71 & 0,02 & 240 & 192 & 384 & 83 & 97 \\
\hline Sông & N7 & NL & 7,91 & 0,07 & $\mathrm{KPH}$ & 0,07 & 0,07 & 5,1 & 2,8 & 6,8 & 0,05 & 0,59 & 0,02 & 290 & 138 & 276 & 87 & 98 \\
\hline Lòng Tàu & N7 & NR & 7,90 & 0,07 & $\mathrm{KPH}$ & 0,07 & 0,07 & 5,1 & 3,2 & 6,3 & 0,06 & 0,74 & 0,02 & 240 & 138 & 276 & 87 & 97 \\
\hline Sông & $\mathrm{CM}$ & $\mathrm{NL}$ & 8,24 & - & - & - & - & 5,4 & 2,3 & 5,6 & 0,06 & 0,34 & 0,02 & 210 & 169 & 338 & 85 & 98 \\
\hline Thị Vải & $\mathrm{CM}$ & NR & 8,26 & 0,01 & $\mathrm{KPH}$ & 0,06 & 0,07 & 5,2 & 2,2 & 5,5 & 0,04 & 0,55 & 0,02 & 210 & 158 & 316 & 86 & 97 \\
\hline
\end{tabular}

Trong đó VC là tỷ lệ phần trăm so với quy chuẩn cho phép; KPH là không phát hiện; NL là nước lớn (triều lên); NR là nước ròng (triều rút); $\mathrm{NB}$ là Nhà Bè; VC là Vàm Cỏ; ĐT là Đồng Tranh; N7 là Ngã Bảy; CM là Cái Mép; TT là Tân Thành; VT là Vũng Tàu.

\subsection{Diễn biến CLN vùng bò̀ TpHCM giai đoạn 2016-2019}

Dữ liệu quan trắc tại thời điểm triều kém được sử dụng để đánh giá diễn biến CLN vùng bờ TpHCM giai đoạn 2016-2019 thông qua chỉ số WQI.5 (Bảng 6-7).

Diễn biến theo năm: Nhìn chung xu hướng tăng/ giảm CLN chưa thực sự rõ ràng, đặc biệt khi so sánh giữa các năm bởi sự khiếm khuyết dữ liệu vào 2016 và 2018. Dũ liệu quan trắc liên tục từ 5/2016-5/2018 cho thấy dấu hiệu cải thiện CLN trên các sông lớn và vùng cửa sông, nhất là cuối 2016 sang nửa đầu 2017. Tuy nhiên, do trao đổi nước kém, CLN nội đồng (trạm TTH) có xu thế suy giảm-từ mùa mưa 2017 đến đầu mùa khô 2018 và 2019.

Diễn biến CLN giữa 2 mùa trong năm: Bảng 6 và Hình 5 cho thấy CLN vào mùa mưa thường kém hơn mùa khô, do chất ô nhiê̂m dễ dàng bị nước mưa rửa trôi và lôi cuốn theo 
dòng chảy đổ vào nguồn tiếp nhận. Phân bố CLN tại vùng bờ TpHCM vào mùa mưa như sau: khu vực thượng nguồn và các sông rạch nội đồng có CLN trung bình (chủ yếu do $\mathrm{pH}$, $\mathrm{DO}, \mathrm{N}-\mathrm{NH}_{4}{ }^{+}$, Coliform không đáp ứng quy chuẩn); hạ lưu sông Soài Rạp có CLN khá (do $\mathrm{pH}, \mathrm{DO}$, Coliform); khu vực cửa sông (Đồng Tranh, Ngã Bảy, Cái Mép) đổ ra vùng ven biển có CLN ở mức tốt. Trong mùa khô, CLN chủ yếu ở mức tốt; riêng thượng nguồn sông Lòng Tàu, hạ nguồn sông Đồng Tranh và Soài Rạp có CLN ở mức khá (do pH, DO, Coliform).

Bảng 6. Diễn biến CLN vùng bờ TpHCM tại thời điểm triều rút (WQI.5).

\begin{tabular}{|c|c|c|c|c|c|c|}
\hline \multirow{2}{*}{ Trạm } & 2016 & \multicolumn{3}{|c|}{2017} & \multirow{2}{*}{$\begin{array}{c}2018 \\
\text { Mùa khô }\end{array}$} & \multirow{2}{*}{$\begin{array}{c}2019 \\
\text { Mùa khô }\end{array}$} \\
\hline & Mùa mưa & Mùa khô & Mùa mưa & Năm & & \\
\hline NB & 45 & 69 & 72 & 69 & 82 & 91 \\
\hline TTH & 51 & 75 & 83 & 76 & 74 & 53 \\
\hline $\mathrm{VC}$ & 67 & 72 & 72 & 73 & 74 & 74 \\
\hline VS & 74 & 82 & 74 & 75 & 74 & 91 \\
\hline ĐT & 92 & 89 & - & - & - & 92 \\
\hline N7 & 93 & 84 & 78 & 78 & 89 & 91 \\
\hline $\mathrm{CM}$ & 92 & 91 & 100 & 92 & 89 & 83 \\
\hline $30 / 4$ & - & 82 & 84 & 77 & 92 & 89 \\
\hline C.CM & - & 88 & 77 & 70 & 85 & 83 \\
\hline $\mathrm{CT}$ & - & 93 & 77 & 78 & 93 & 89 \\
\hline $\mathrm{ÐH}$ & - & 80 & 69 & 69 & 92 & 91 \\
\hline C.ĐT & - & 84 & 69 & 70 & 93 & 91 \\
\hline HNPN & - & 84 & 77 & 70 & 92 & 89 \\
\hline C.LT & - & 86 & 69 & 71 & 91 & 83 \\
\hline
\end{tabular}
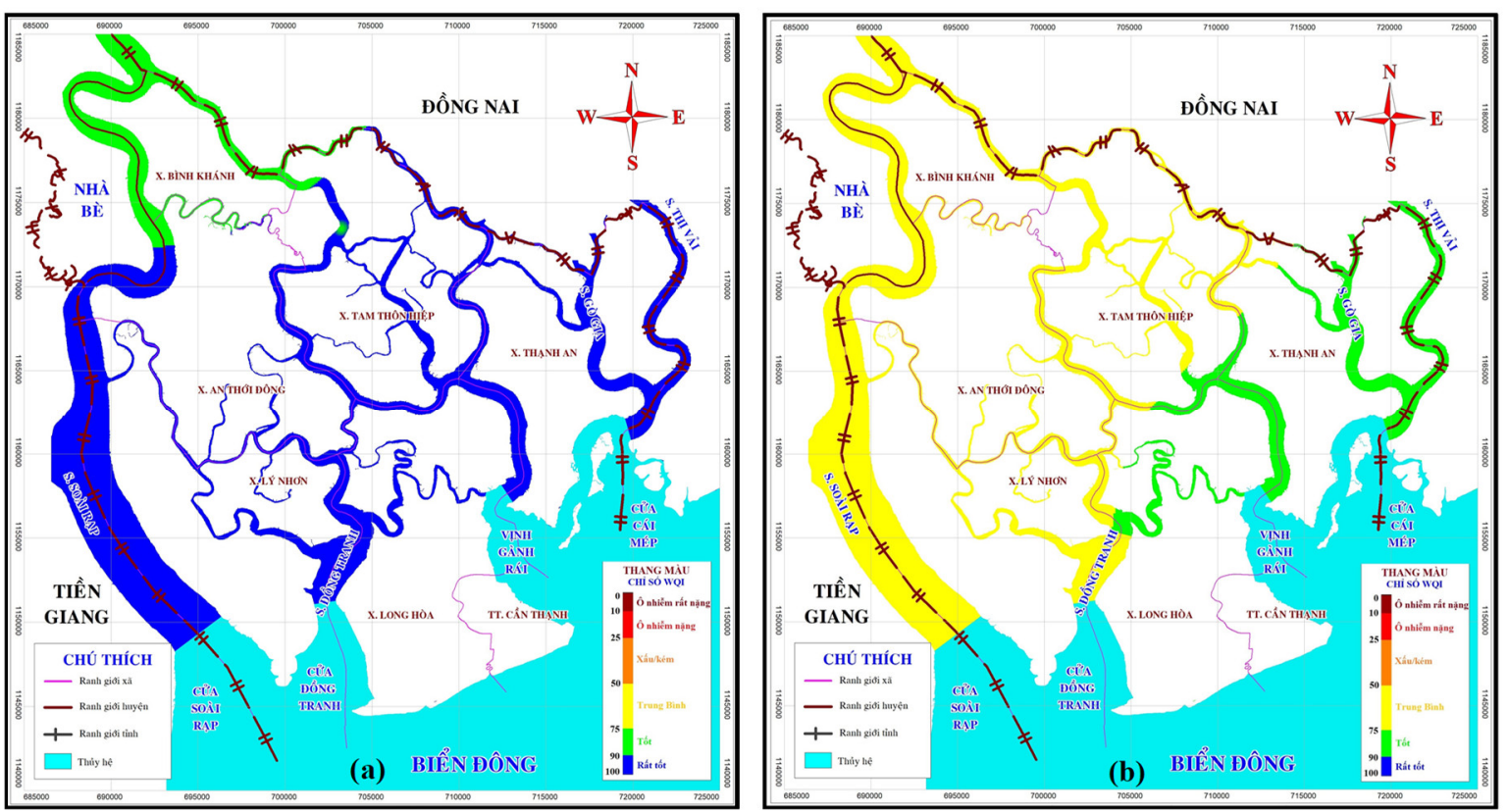

Hình 5. Chỉ số chất lượng NMLĐ vùng bờ năm 2017 (WQI.2): (a) Mùa Khô; (b) Mùa mưa.

Diễn biến CLN theo các tháng trong năm: Bảng 7 cho thấy diễn biến CLN theo tháng tại khu vực lục địa rõ nét hơn vùng biển ven bờ. Chất lượng nước mặt lục địa thường suy giảm vào các tháng cuối mùa khô chuyển sang mùa mưa (T5-T7) do tiếp nhận nhiều chất ô nhiễm bị lôi cuốn theo dòng chảy mặt. CLN vào T6-T7 thường thấp nhất năm (dao động từ trung bình-khá), dần cải thiện vào cuối mùa mưa (T9-T11, CLN khá-tốt), sau đó suy giảm ở nửa đầu mùa khô (T12-T2, CLN trung bình-khá), nhất là khu vực nội đồng (tiếp nhận đáng kể tải lượng chất ô nhiễm do nhu cầu sử dụng nước gia tăng trong mùa lễ tết) và chuyển biến 
tích cực ở các tháng sau đó (T3-T5, CLN khá-tốt). Trong những tháng mùa khô, CLN tại một số thời điểm bị ảnh hưởng tiêu cực do suy giảm dòng chảy môi trường, giảm khả năng trao đổi nước hoặc tiếp nhận chất ô nhiễm bị lôi cuốn sau một vài trận mưa nghịch mùa.

Bảng 7. Diễn biến CLN vùng bờ Tp.HCM theo các tháng trong năm tại thời điểm triều rút (WQI.5).

\begin{tabular}{|c|c|c|c|c|c|c|c|c|c|c|c|c|c|c|c|c|c|c|c|c|c|c|c|c|c|c|c|c|c|}
\hline \multicolumn{9}{|c|}{2016} & \multicolumn{12}{|c|}{2017} & \multicolumn{5}{|c|}{2018} & \multicolumn{4}{|c|}{2019} \\
\hline Trạm & T5 & T6 & T7 & T8 & T9 & T10 & T11 & T12 & T1 & $\mathrm{T} 2$ & T3 & $\mathrm{T} 4$ & T5 & T6 & T7 & T8 & T9 & T10 & T11 & T12 & T1 & $\mathrm{T} 2$ & T3 & T4 & T5 & T1 & $\mathrm{T} 2$ & T3 & T4 \\
\hline $\mathrm{NBe}$ & 62 & 74 & 50 & 37 & 32 & 66 & 42 & 91 & 49 & 51 & 67 & 65 & 88 & 49 & 60 & 81 & 69 & 81 & 85 & 61 & 81 & 79 & 74 & 91 & 82 & 90 & 89 & 80 & 100 \\
\hline TTH & 100 & 87 & 100 & 34 & 51 & 49 & 45 & 65 & 73 & 86 & 90 & 100 & 79 & 79 & 90 & 86 & 80 & 75 & 79 & 90 & 62 & 90 & 79 & 90 & 92 & 48 & 66 & 85 & 71 \\
\hline VC & 91 & 87 & 77 & 52 & 59 & 51 & 61 & 60 & 69 & 71 & 73 & 80 & 65 & 65 & 67 & 65 & 69 & 66 & 79 & 69 & 73 & 100 & 91 & 84 & 69 & 90 & 90 & 79 & 67 \\
\hline VS & 86 & 80 & 100 & 67 & 74 & 63 & 86 & 78 & 67 & 74 & 79 & 79 & 77 & 60 & 69 & 72 & 67 & 100 & 85 & 67 & 100 & 89 & 90 & 84 & 91 & 83 & 77 & 90 & 100 \\
\hline ĐT & 100 & 100 & 100 & 100 & 86 & 89 & 100 & 86 & - & - & - & - & - & - & 86 & 86 & 87 & 88 & & - & - & - & - & - & - & 81 & 86 & 100 & 100 \\
\hline N7 & 100 & 100 & 89 & 100 & 100 & 100 & 100 & 100 & 100 & 79 & 89 & 90 & 87 & 100 & 100 & 90 & 90 & 79 & 100 & 100 & 90 & 100 & 91 & 76 & 90 & 87 & 100 & 100 & 90 \\
\hline $\mathrm{CM}$ & 100 & 85 & 89 & 100 & 100 & 74 & 100 & 88 & 90 & 84 & 90 & 100 & 100 & 90 & 90 & 100 & 80 & 91 & 90 & 86 & 89 & 100 & 82 & 68 & 90 & 89 & 100 & 100 & 90 \\
\hline $30 / 4$ & - & - & - & - & - & - & - & - & 64 & 100 & 100 & 100 & 100 & 100 & 80 & - & 100 & 79 & 79 & 100 & 100 & 100 & 89 & 100 & - & - & - & 88 & 90 \\
\hline C.CM & - & - & - & - & - & - & - & ....... & 80 & 100 & 100 & 79 & 100 & 100 & 100 & - & 89 & 89 & 77 & 100 & 89 & 89 & 90 & 90 & - & - & - & 83 & 89 \\
\hline CT & - & - & - & - & - & - & - & - & 89 & 100 & 100 & 100 & 100 & 87 & 100 & - & 100 & 89 & 90 & 100 & 100 & 100 & 100 & 88 & - & - & - & 89 & 90 \\
\hline ĐH & - & - & - & - & - & - & .... & - & 64 & 100 & 87 & 86 & 100 & 89 & 100 & - & 89 & 100 & 72 & 100 & 100 & 89 & 100 & 89 & - & .... & .... & 89 & 92 \\
\hline C.ĐT &.- & - & - & - & - & - & - & - & 90 & 89 & 89 & 86 & 100 & 100 & 86 & - & 89 & 89 & 73 & 100 & 90 & 89 & 90 & 100 & - & - & - & 91 & 89 \\
\hline Ne & - & - & - & - & - & - & - & - & 90 & 100 & 87 & 100 & 90 & 100 & 87 & - & 90 & 90 & 90 & 90 & 100 & 89 & 90 & 100 & - & - & & 83 & 89 \\
\hline C.LT & - & - & - & - & - & - & - & - & 100 & 100 & 89 & 79 & 100 & 90 & 74 & - & 89 & 89 & 78 & 100 & 89 & 100 & 89 & 89 & - & - & - & 89 & 89 \\
\hline
\end{tabular}

\subsection{So sánh các kết quả tính toán chỉ số CLN}

Bảng 8 trình bày kết quả tính toán chỉ số CLN tại vùng bờ TpHCM vào mùa khô 2018 (12/2017-05/2018) theo các cách tiếp cận khác nhau.

Bảng 8. So sánh các chỉ số CLN tại vùng bờ TpHCM vào mùa khô năm 2018 .

\begin{tabular}{|c|c|c|c|c|c|c|c|c|c|c|}
\hline \multirow{2}{*}{ Trạm } & \multicolumn{4}{|c|}{ CCME } & \multicolumn{3}{|c|}{ QĐ1460 } & \multicolumn{3}{|c|}{ QĐ1460 vs. CCME } \\
\hline & WQI.5 & WQI.4 & WQI.6 & $\%$ & WQI.2 & WQI.7 & $\%$ & WQI.2 & WQI.3 & $\%$ \\
\hline NB & 82 & 66 & - & -19 & 63 & 85 & -35 & 63 & 64 & +2 \\
\hline TTH & 74 & 61 & - & -17 & 62 & 81 & -31 & 62 & 60 & +3 \\
\hline $\mathrm{VC}$ & 74 & 57 & - & -22 & 64 & 86 & -34 & 64 & 57 & -10 \\
\hline VS & 74 & 64 & - & -13 & 60 & 78 & -30 & 60 & 63 & +5 \\
\hline N7 & 89 & 67 & - & -24 & 63 & 83 & -32 & 63 & 67 & +6 \\
\hline $\mathbf{C M}$ & 89 & 60 & - & -32 & 53 & 61 & -15 & 53 & 56 & +5 \\
\hline $30 / 4$ & 92 & - & 92 & 0 & - & - & - & - & - & - \\
\hline C.CM & 85 & - & 79 & -7 & - & - & - & - & - & - \\
\hline CT & 93 & - & 86 & -7 & - & - & - & - & - & - \\
\hline ĐH & 92 & - & 86 & -6 & - & - & - & - & - & - \\
\hline C.ĐT & 93 & - & 86 & -7 & - & - & - & - & - & - \\
\hline HNPN & 92 & - & 93 & +1 & - & - & - & - & - & - \\
\hline C.LT & 91 & - & 86 & -5 & - & - & - & - & - & - \\
\hline
\end{tabular}

Một số nhận định được rút ra như sau:

- WQI.2 và WQI.3 lần lượt được tính toán theo Quyết định 1460/QĐ-TCMT và mô hình WQI_CCME với cùng bộ thông số và dữ liệu quan trắc, theo đó, các kết quả tính toán chênh lệch không đáng kể (dao động từ 2-10\%).

- Các giá trị WQI.5, WQI.4 và WQI.6 cho thấy, mặc dù đều tính toán bằng WQI_CCME, các tổ hợp thông số khác nhau sẽ cho các kết quả khác nhau về chỉ số CLN. Đối với WQI.5 vs. WQI.6, ít khác biệt về các thông số giữa hai tổ hợp (As và dầu mỡ), với nồng độ ít ảnh hưởng đến kết quả tính toán (đạt quy chuẩn), theo đó, các chỉ số CLN tương đối giống nhau (sai khác từ 0-7\%). 
- Tuy nhiên, khi hai tổ hợp thông số khác nhau đáng kể về số lượng (WQI.5 vs. WQI.4, 07 thông số khác biệt), chênh lệch giữa các chỉ số CLN theo đó rất đáng quan tâm, dao động từ $13-32 \%$ (chủ yếu chi phối bởi Mn và E.Coli), có khả năng thay đổi mức CLN. Nhận định tương tự được chỉ ra khi so sánh WQI.2 và WQI.7 (tính toán theo Quyết định 1460/QĐTCMT với 05 thông số khác biệt), sai khác giữa các chỉ số CLN dao động từ $15-35 \%$ (chủ yếu do E.Coli).

- Một cách tổng quát, các cách tiếp cận (công thức) và/hoặc các tổ hợp thông số khác nhau (số lượng) có thể dẫn đến những sai khác trong nhận định về mức CLN. Các phép so sánh chỉ ra rằng tổ hợp các thông số tính toán chỉ số CLN nên tối ưu về số lượng, đại diện đầy đủ các tính chất lý, hoá, sinh của nguồn nước, phản ánh đặc điểm nguồn tiếp nhận. Trong điều kiện đó, Quyết định 1460/QĐ-TCMT và mô hình WQI_CCME cho kết quả tính toán chỉ số CLN khá tương đồng. Nhìn chung, để đánh giá và phản ánh đồng bộ CLN tại vùng bờ TpHCM, khuyến nghị sử dụng chỉ số WQI-CCME trong điều kiện xem xét tối đa và nhất quán các thông số quan trắc chất lượng nước mặt lục địa và nước biển ven bờ.

\section{Kết luận}

Mùa khô 2019, CLN lục địa đáp ứng mục đích tưới tiêu và thuỷ lợi ngoại trừ dấu hiệu ô nhiễm $\mathrm{Pb}$ tại hạ lưu sông Vàm Cỏ và sông Lòng Tàu, TSS tại vùng cửa sông ven biển. Càng về phía biển, CLN càng được cải thiện, đảm bảo cho nuôi trồng thuỷ sản và bảo tồn thuỷ sinh ven bờ. CLN ở thời điểm triều rút thường kém hơn khi triều cường, đặc biệt tại các sông rạch nội đồng. CLN vùng bờ TpHCM đáng quan tâm tại hạ lưu sông Soài Rạp (sau hợp lưu với sông Vàm Cỏ) và cửa sông Đồng Tranh... Giai đoạn 2016-2019, CLN trên các sông lớn và khu vực cửa sông dần được cải thiện (từ cuối 2016 sang nửa đầu 2017), trái ngược với khu vực nội đồng (từ mùa mưa 2017 đến đầu mùa khô 2018 và 2019). CLN vào mùa mưa (đặc biệt vào $\mathrm{T} 5-\mathrm{T} 7$ ) thường kém hơn mùa khô (khá-tốt); đạt mức trung bình tại khu vực thượng nguồn, mức khá tại hạ lưu sông Soài Rạp, mức tốt ở vùng cửa sông, ven biển và các vịnh. Kết quả nghiên cứu cũng cho thấy trong điều kiện xem xét tối đa và nhất quán các thông số quan trắc, chỉ số WQI-CCME linh hoạt hơn khi ứng dụng đánh giá CLN trong phạm vi gồm nhiều loại đối tượng tiếp nhận (như nước mặt lục địa, nước biển ven bờ) hay khi cơ sở dữ liệu quan trắc đồ sộ, thống kê trong nhiều năm.

Đóng góp của tác giả: Xây dựng ý tưởng nghiên cứu, Viết bản thảo bài báo, Chỉnh sửa bài báo: L.N.T.; Lựa chọn phương pháp nghiên cứu, Xử lý số liệu: Đ.T.H.; Lấy mẫu, Phân tích mẫu: Viện Khí Tượng Thủy văn Hải văn và Môi trường.

Lời cảm ơn: Nghiên cứu này được tài trợ bởi Sở Khoa học và Công nghệ thành phố Hồ Chí Minh trong khuôn khổ Nhiệm vụ nghiên cứu KH\&CN "Đánh giá khả năng chịu tải của vịnh Đồng Tranh, vịnh Gành Rái và cửa sông Soài Rạp trước sức ép của sự gia tăng dân số và tăng trưởng kinh tế của vùng hạ lưu hệ thống sông Đồng Nai”.

Lời cam đoan: Tập thể tác giả cam đoan bài báo này là công trình nghiên cứu của tập thể tác giả, chưa được công bố ở đâu, không được sao chép từ những nghiên cứu trước đây; không có sự tranh chấp lợi ích trong nhóm tác giả.

\section{Tài liệu tham khảo}

1. Meybeck, M.; Kuusisto, E.; Mäkelä, A.; Mälkki, E. Water Quality Monitoring - A Practical Guide to the Design and Implementation of Freshwater Quality Studies and Monitoring Programmes. UNEP/WHO, 1996.

2. Cooke, S.E.; Ahmed, S.M.; MacAlpine, N.D. Introductory guide to surface water quality monitoring in agriculture. Conservation and development branch, Alberta Agriculture, Food and Rural Development. Edmonton, Alberta, Australia, 2000. 
3. Trình, L. Nghiên cứu phân vùng chất lượng nước theo các chỉ số chất lượng nước (WQI) và đánh giá khả năng sử dụng các nguồn nước sông, kênh, rạch ở thành phố Hồ Chí Minh, 2006.

4. Curtis G.C. Oregon Water Quality Index: a Tool for Evaluating Water Quality Manegment Effectiveness. Journal of the American water resources association, 2001.

5. Tania, M.; Radu, M.; Dan, V.; Rodica, V.; Mihnea, M. Water quality assessment of the Nadas River in terms of NFS Water quality. Analele Universităţii din Oradea, Fascicula Protecţia Mediului 2013, 21, 649-654.

6. Sharmaa, P.; Meher, P.K.; Kumar, A.; Gautam, Y.P.; Mishra, K.P. Changes in water quality index of Ganges River at different locations in Allahabad. Sustainability Water Qual. Ecol. 2014, 3-4, 67-76.

7. Swamee, P.; Tyagi, A. Improved method for aggregation of water quality subindices. J. Environ. Eng. 2007, 133, 220-225.

8. Sarkar, C.; Abbasi, S.A. Qualidex - A new software for generating water quality indices. Environ. Monit. Assess. 2006, 119, 201-231.

9. Štambuk-Giljanović, N. Comparison of Dalmatian water evaluation indices. Water Environ. Res. 2003, 75, 388-405.

10. Sutadian, A.D., Muttil, N.; Yilma, A.; Perer, C. Development of River Water Quality Indices - A Review. Environ. Monit. Assess. 2016, 188, 158.

\title{
Evolution of water quality in the coastal area in Ho Chi Minh City during the period of 2016-2019
}

\author{
Le Ngoc Tuan ${ }^{1}$, Doan Thanh Huy ${ }^{2}$ \\ ${ }^{1}$ University of Science (VNU-HCMC); lntuan@hcmus.edu.vn \\ ${ }^{2}$ Institute of Meteorology Hydrology Oceanography and Environment; \\ dthanhhuy132@gmail.com
}

\begin{abstract}
In the context of fast population growth and economic development in the SaigonDong Nai River basin, the WQI (Vietnam) and CCME (Canada) indices were used to assess the evolution of coastal water quality in Ho Chi Minh City for the period of 2016-2019 based on periodical monitoring data (14 stations) and additional measurements ( 22 stations). In general, water quality gradually increased towards the sea and met the water use objectives (except for $\mathrm{Pb}$ in the downstream of Vam Co river, Long Tau river; TSS in the estuary and coastal areas). The water quality at low tide was usually worse than that at high tide (clearly recognized in inland rivers). The same trend was found in the rainy season (average-fair level) as compared to the dry (fair-good level). Recently, there have been signs of improved water quality in some estuaries and coastal areas, however, it is necessary to continuously strengthen and maintain the management of coastal water quality $\left(\mathrm{pH}, \mathrm{DO}, \mathrm{N}_{-} \mathrm{NH}_{4}^{+}\right.$, Coliform, E.Coli, $\mathrm{Pb}, \mathrm{Mn}$ ), especially in the upstream of Long Tau river, Soai Rap river, Dong Tranh estuary... In addition, it is recommended to use the CCME index in assessing coastal water quality to simultaneously consider the water quality in the continental and coastal areas. In order to improve management efficiency, it is necessary to study and evaluate the wastewater emission, surface water quality, and the load-carrying capacity of the area in the following years.
\end{abstract}

Keywords: Water quality index; Environmental pollution; Surface water; Coastal area. 